\title{
EDITORIAL
}

\section{Statistically significant or clinically useful? From population studies to patient care}

\author{
V. Brusasco
}

I $\mathrm{n}$ the last few years, great attention has been paid to a variety of comorbid conditions that are frequently observed in patients with known chronic obstructive pulmonary disease (COPD). Although the term comorbidity literally refers to a disease occurring simultaneously with and usually independently of another medical condition [1], it has been used to lend support to the hypothesis that COPD is a component of a chronic systemic inflammatory syndrome involving several organs [2] and to a change in the COPD definition [3]. In this scenario, systemic inflammation would be a cause rather than a consequence of COPD and the C-reactive protein (CRP) has been proposed as one of the major culprits [4]. However attractive, this hypothesis was only based on cross-sectional population studies, which were designed to show associations but not causality.

Among the reported COPD comorbidities are both cachexia and obesity. Whereas the former can be regarded as a consequence of severe COPD, the relationship between obesity and COPD is not clear. In a large population study, LANDBO et al. [5] found a monotonically inverse relationship between body mass index (BMI) and mortality in subjects with severe COPD, thus suggesting that optimal BMI in these patients is not between 21 and $25 \mathrm{~kg} \cdot \mathrm{m}^{-2}$, as in general population, but it may extend to overweight and even mild obesity. These findings are in line with those of ScHOLs et al. [6], who found that not only high BMI but also weight gain $>2 \mathrm{~kg}$ in 8 weeks was associated with better survival in patients with moderateto-severe COPD. In a paper published in the current issue of the European Respiratory Journal, BRIDEVAUX et al. [7] report that weight gain is an independent predictor of systemic inflammation in COPD patients, as inferred from elevated highsensitivity CRP. If the conclusions of this and previous studies $[5,6]$ are correct, then some questions need to be adequately addressed before clinically useful inferences are made. First, how can an increased BMI be associated with a longer survival and an increased CRP at the same time? Secondly, does CRP play a causal role or is it just a marker of the inflammation associated with COPD? Thirdly, should individual COPD patients be treated with energy supplementation or restriction?

The above questions cannot be answered at this time for several reasons. First, although the study by BRIDEVAux et al. [7]

Dept of Internal Medicine, Medical School, University of Genoa, Genoa, Italy.

CORRESPONDENCE: V. Brusasco, Padiglione Maragliano, Ospedale San Martino, Largo R. Benzi, 10, 16132 Genova, Italy. E-mail: vito.brusasco@unige.it was based on the assumption that increased CRP is associated with a high risk of cardiovascular mortality, this important patient-centred outcome was surprisingly not considered. Moreover, the association between CRP and mortality in COPD was reported in population studies [8, 9] but not confirmed in a recent study on well characterised COPD patients [10]. Secondly, COPD was defined as fast forced expiratory volume in $1 \mathrm{~s}$ (FEV1) decline, which is different from the usual definition based on the reduction of FEV1/vital capacity (VC) together with consistent clinical data. That this difference is not marginal is shown by the fact that more than half of the subjects defined as COPD by fast FEV1 decline still had an FEV1/forced vital capacity (FVC) $>0.7$ in the second survey, thus not matching the criteria for the diagnosis of COPD established by the Global Initiative for Chronic Obstructive Lung Disease (GOLD) committee [11]. Although the definition of airflow obstruction has also been challenged [12], this makes the comparisons with previous studies problematic. Moreover, it is surprising to see that more than one fourth of males and almost half of females with fast FEV1 decline never smoked. One explanation for these inconsistencies may be that large weight gain is by itself associated with an increased decline in lung function [13-16] and possibly dyspnoea on walking. Thus, subjects becoming obese could have been wrongly classified as COPD. Thirdly, the primary outcome of the study, i.e. CRP, was measured only at followup, whereas FEV1 and BMI were measured both in the first and second surveys. Because of the many sources of inter- and intra-individual variability, the value of single CRP measurements is questionable [17]. Thus, this study leaves the specific question addressed in the introduction, whether body weight gain modifies systemic inflammation in COPD, unanswered. In addition, the lack of initial measurements of CRP does not allow lending support to the hypothesis of COPD as a component of a systemic inflammatory syndrome [1].

From a practical point of view, results from the study by BRIDEVAUX et al. [7] suggesting that females with weight gain and fast FEV1 decline should have CRP measured to better predict incident cardiovascular events must be interpreted with caution. This inference is based on changes of FEV1 and body weight recorded at $\sim 11$-yr intervals in a population with relatively normal lung function in the first survey. Because of the large intra-individual variability, the year-to-year changes in FEV1 over 1 yr FEV1 should exceed $15 \%$ before confidence can be given that a clinically meaningful change has in fact occurred in an individual [18]. For this reason, serial measurements over $\geqslant 3$ yrs are generally required to reliably determine 
the rate of decline in lung function. Likewise, a $14 \%$ weight gain over $10 \mathrm{yrs}$ in an average subject with a body weight of $70 \mathrm{~kg}$ would correspond to $<1 \mathrm{~kg} \cdot \mathrm{yr}^{-1}$, which is close to the diurnal variability. Finally, changes in body weight should be interpreted in relation to BMI as the clinical significance of a weight gain of $>14 \%$ in an underweight patient is likely to be very different from the same change occurring in an obese patient.

In conclusion, considering the data presented by BRIDEVAUX et al. [7] in the current issue of the European Respiratory Journal, a word of caution must be raised regarding the possible enthusiasm fostered by highly significant differences resulting from posthoc analyses of population studies not properly designed to answer specific questions. A basic concept a clinician should bear in mind in interpreting population studies is that statistics do not always tell us the truth [19] and statistical significance does not necessarily embody clinical relevance, particularly when the sample size is large and the resulting differences are too small to be appreciated in single patients.

\section{STATEMENT OF INTEREST}

A statement of interest for V. Brusasco can be found at www.erj. ersjournals.com $/ \mathrm{misc} /$ statements.dtl

\section{REFERENCES}

1 Merriam-Webster's Online Dictionary. www.merriam-webster.com Date last updated: July, 2003. Date last accessed: May 19, 2009.

2 Fabbri LM, Rabe KF. From COPD to chronic systemic inflammatory syndrome? Lancet 2007; 370: 797-799.

3 Rabe KF, Hurd S, Anzueto A, et al. Global strategy for the diagnosis, management, and prevention of COPD: GOLD executive summary. Am J Respir Crit Care Med 2007; 176: 532-555.

4 Fabbri LM, Luppi F, Beghé B, et al. Complex chronic comorbidities of COPD. Eur Respir J 2008; 31: 204-212.

5 Landbo C, Prescott E, Lange P, et al. Prognostic value of nutritional status in chronic obstructive pulmonary disease. Am J Respir Crit Care Med 1999; 160: 1856-1861.
6 Schols AMJ, Slangen L, Volovics, et al. Weight loss is a reversible factor in the prognosis of chronic obstructive pulmonary disease. Am J Respir Crit Care Med 1998; 157: 1791-1797.

7 Bridevaux P-O, Gerbase MW, Schindler C, et al. Sex-specific effect of body weight gain on systemic inflammation in subjects with COPD: results from the SAPALDIA cohort study 2. Eur Respir $J$ 2009; 34: 332-339.

8 Man SF, Connett JE, Anthonisen NR, et al. C reactive protein and mortality in mild to moderate chronic obstructive pulmonary disease. Thorax 2006; 61: 849-853.

9 Dahl M, Vestbo J, Lange P, et al. C-reactive protein as a predictor of prognosis in COPD. Am J Respir Crit Care Med 2007; 175: 250-255.

10 de Torres JP, Pinto-Plata V, Casanova C, et al. C-reactive protein levels and survival in patients with moderate to very severe COPD. Chest 2008; 133: 1336-1343.

11 Pauwels RA, Buist AS, Calverley PM, et al. Global strategies for the diagnosis, management, and prevention of chronic obstructive pulmonary disease. NHLBI/WHO Global Initiative for Chronic Obstructive Lung Disease (GOLD) Workshop summary. Am J Respir Crit Care Med 2001; 163: 1256-1276.

12 Pellegrino R, Brusasco V, Viegi G, et al. Definition of COPD: based on evidence or opinion? Eur Respir J 2008; 31: 681-682.

13 Chinn DJ, Cotes JE, Reed JW. Longitudinal effects of change in body mass on measurements of ventilatory capacity. Thorax 1996; 51: 674-699.

14 Chen Y, Horne SL, Dosman JA. Body weight and weight gain related to pulmonary function decline in adults: a six year follow up study. Thorax 1993; 48: 375-380.

15 Carey IM, Cook DG, Strachan DP. The effects of adiposity and weight change on forced expiratory volume decline in a longitudinal study in adults. Int J Obes Relat Metab Disord 1999; 23 : 979-985.

16 Pistelli F, Bottai M, Carrozzi L, et al. Changes in obesity status and lung function decline in a general population sample. Respir Med 2008; 102: 674-680.

17 Donaldson G. C-reactive protein: does it predict mortality? Am J Respir Crit Care Med 2006; 175: 209-210.

18 Pellegrino R, Viegi G, Brusasco V, et al. Interpretative strategies for lung function tests. Eur Respir J 2005; 26: 948-968.

19 Huff D. How to Lie with Statistics. New York, Norton, 1954. 